\title{
A NOÇÃO DE CONHECIMENTO DA EDUCAÇÃO FÍSICA ABORDADO NA FORMAÇÃO CONTINUADA EM SANTA CATARINA
}

\author{
VANIA VITORIO 1 \\ ANA LÚCIA CARDOSO ${ }^{2}$ \\ CARLOS AUGUSTO EUZÉBIO ${ }^{3}$ \\ SIRLÉIA SILVANO ${ }^{4}$ \\ SÔNIA SILVEIRA GONÇALVES ${ }^{5}$ \\ GUILHERME NEVES ${ }^{6}$
}

A formação continuada é assunto amplo e recorrente no meio educacional, o que aciona estudos e pesquisas para sua explanação. Não tão frequente é o debate sobre o conhecimento que permeia as formações, intenção deste estudo que objetiva conhecer a formação continuada em Santa Catarina que contemplou professores de educação física entre 2003 e 2010.

O foco central da pesquisa de mestrado foi a análise da noção de conhecimento em educação física abordado na formação continuada a partir do exposto pelos formadores quanto à seleção, organização, sistematização, abordagem dos conteúdos e sua direção teórico-metodológica, com o intuito de explicitar o conhecimento em educação física abordado nas formações e verificar se o mesmo se articula com os pressupostos da Proposta Curricular. Nesse sentido, recorremos a György Lukács em sua ontologia do ser social, e a Roy Bhaskar em sua ontologia do realismo transcendental.

Inicialmente foram solicitados, a todas as Secretarias de Desenvolvimento Regional/Gerências Regionais de Educação de Santa Catarina (SDR/GEREDS) os documentos referentes às formações entre $2003 \mathrm{e}$ 2010 que envolveram professores de educação física. Estabelecidos critérios de seleção tivemos sessenta e uma formações. Após fizemos o levantamento dos formadores que efetivaram. Tivemos sessenta e dois formadores.

\footnotetext{
${ }^{1}$ Docente da Universidade do Extremo Sul Catarinense (UNESC) - vvi@unesc.net

${ }^{2}$ Docente da Universidade do Extremo Sul Catarinense (UNESC) - anc@unesc.net

${ }^{3}$ Docente da Universidade do Extremo Sul Catarinense (UNESC) - cae@unesc.net

${ }^{4}$ Docente da Rede Pública Municipal de Criciúma - sirleia.silvano@gmail.com

${ }^{5}$ Mestranda PPGE (UNESC) - soniahoje@bol.com.br

6 Mestrando PPGE (UNESC) - guilherme.neves @hotmail.com
} 
Contamos um formador por curso e não contamos formadores repetidos, que realizaram vários cursos, ficando um total de vinte e oito formadores.

A seleção dos formadores para a entrevista foi a partir do currículo lattes e mais um por relevância para o problema da pesquisa. Tivemos onze formadores, destes nove participaram da entrevista. A opção por entrevista se deu porque os documentos, em sua maioria, não continham informações que explicitassem com clareza o conhecimento da educação física que fora tratado. Para a análise dos dados optamos, primeiramente, por descrever os elementos centrais das formações realizadas pelos formadores, que nos auxiliaram, na sequência, na análise das questões do conhecimento.

A partir desses elementos centrais chegamos a dois blocos de análise. Um, da estrutura e seu propósito: caracterização dos formadores, a formação acadêmica e a atuação profissional; e da organização/sistematização da formação realizada em relação a tema, continuidade, direção, escolha dos formadores, períodos de tempo. Outro, das formações: da noção de conhecimento abordado nas formações, em que evocamos os critérios de seleção de conteúdo, conteúdo, procedimento didático e a relação entre a Proposta Curricular de Santa Catarina (PCSC) e a formação.

Nossa opção por considerar a noção de conhecimento abordado nas formações nos conduziu a conhecer alguns dados que respondessem à inquietação sobre se de fato temos formação continuada efetiva. Certificamonos de que temos formação continuada, mas caracterizada como a continuidade da descontinuidade da formação. Tal condição não se articula a um projeto de mudança desta realidade e expressa o grande desafio em consolidar uma Proposta com bases teóricas materialista-históricas que são paradoxais às políticas de governo liberais, que atendem aos interesses da minoria no poder em detrimento da maioria que compõe a sociedade.

A sistematização das formações não favorece a abordagem do conhecimento com a continuidade e profundidade necessárias para conhecer a realidade e questionar os problemas históricos deste modelo de sociedade. A formação continuada dá continuidade aos conhecimentos segmentados, não percebendo o processo como um complexo da formação dos professores. Busca soluções imediatas de problemas imediatos que não consegue resolver, 
uma vez que a formação dos professores não ocorre na "soma" de possíveis soluções de problemas isolados, e sim pela compreensão da totalidade.

Cinco formações abordaram o conteúdo no aspecto teóricometodológico. Quanto à articulação com a matriz da Proposta: três ficaram dispersas, uma nos limites da Proposta e uma se articulou. Quatro delas não apontam como orientação teórico-filosófica o materialismo histórico - e não vislumbram um projeto de sociedade emancipada. Está ausente a compreensão ontológica de sociedade, o que não permite estabelecer a sociedade almejada como possibilidade no campo da luta de classes, que é um dos parâmetros para a seleção do conhecimento a ser tratado no cotidiano escolar.

Têm destaque e orientam três formações a problematização, a reflexão e o respeito aos conhecimentos que o professor possui como relevantes para o professor perceber a própria prática. Esses elementos ganham importância como ponto de partida, mas é imprescindível a acepção de aonde se quer chegar - oculta nas falas dos formadores

Sem pôr finalidade todo lugar é lugar, inclusive o em que se encontra o que inutiliza e apazigua o caminhar. Para que a teleologia possa se efetivar objetivamente, é necessário que a consciência capte os nexos causais que orientem a busca dos meios para que a finalidade se exteriorize como nova objetividade. Sem esta consciência as causalidades continuam a repousar em si mesmas, ou seja, somente alteram a realidade como mera reação às condições naturais imediatamente postas. (LUKÁCS, 2012)

Nas formações se anuncia o que Moraes (2003) denunciou como esvaziamento do conhecimento na educação, que turva os caminhos à frente e, como consequência, consagra o ceticismo e o pragmatismo que não permitem a compreensão da realidade e acabam no contingente da prática imediata, não transcendendo o presente.

As epistemologias da prática presentes nas formações característica do positivismo e dos "pós-ismos" que, para Moraes (1996), se apresentam como inovadores, mas tem as mesmas perspectivas de esvaziamento do conhecimento científico, teórico e acadêmico na formação de professores que contribui para permanência do controle hegemônico da sociedade - agem como antípodas solidários e realçam o utilitarismo da teoria 
e dos conteúdos, ou seja, ainda que os pós-ismos apresentem-se como críticos do positivismo, possuem a mesma concepção ontológica em relação à constituição do ser social, ou seja, no limite da vida cotidiana.

As epistemologias da prática legitimam e validam o conhecimento fundado na experiência empírica e assim "são incapazes de compreender as estruturas causais dos fenômenos educacionais". (MORAES, 2009, p. 337)

Para o avanço da teoria nos cursos de formação e formação continuada, no sentido do conhecimento crítico, é necessário que filosofia e ciência avancem intensiva e extensivamente, que possibilitem melhor e maior conhecimento dos mecanismos e nexos causais das estruturas do mundo social. (BHASKAR, 1998). Esta condição é fundamental para pôr nova objetividade na educação. "São as formas mais sofisticadas de conhecimento e o alargamento teórico que permitem a ampliação do escopo da práxis humana, possibilitando um aprofundamento da própria ontologia da vida cotidiana." (MORAES, 2009, p. 338)

Das cinco formações que abrangeram o conteúdo no aspecto teórico-metodológico, somente uma se articula aos pressupostos da Proposta com mais profundidade do que apresenta o Documento -, se posiciona quanto à importância do conhecimento para definir e seguir na direção que se quer chegar. Reforça que as coisas não estão prontas, não estão dadas, elas têm que ser feitas e para isso é preciso conhecer a realidade.

As quatro formações com conteúdos específicos da educação física tiveram concepções semelhantes quanto ao conhecimento tratado: três contrariam as bases teóricas da Proposta Curricular e uma para nos seus limites. Os conteúdos abordados pelos formadores apresentam articulação com as propostas pedagógicas: da saúde renovada - um; da psicomotricidade dois; da corporeidade e movimento, aliada ao sócio-construtivismo e à saúde renovada em um ecletismo que dificulta a identificação da perspectiva pedagógica - um. O que elas têm em comum é a associação aos temas da inclusão, da socialização e da ludicidade.

Os conteúdos se ajustam à escola e à sociedade sem questioná-la; especificamente o esporte - por seu caráter hegemônico nas aulas -, passa a ser "novo", inclusivo - paralímpico - mesmo se tratando de práticas esportivas 
que reproduzem os princípios das comparações objetivas e da sobrepujança do "velho" esporte da sociedade capitalista!

As falas sobre a inclusão e socialização não abordam questões sobre: para qual sociedade se quer incluir, socializar? Como é o participar desta sociedade? Sobrepujar? Competir? Quais as possibilidades dos conteúdos da educação física serem tratados como questionamento deste modelo?

Ao desconsiderar estes aspectos a escola adapta, oportuniza, possibilita, mas pouco permite ensinar a compreender a realidade em que está. "Portanto, se diante de toda esta gama de possibilidades ele não atinge a desejada inclusão, isso se deve apenas a ele próprio, a suas limitações incontornáveis" que o deixam fora da sociedade. (SAVIANI, 2008, p. 431).

Inclusão e socialização são termos que indicam fazer parte de um modelo, enquadrar-se - à sociedade. Para isso o esporte pode assumir função elementar de conteúdo sócio-educativo, visto por Bracht (1992) para ensinar as "regras do jogo" social, que existem "os outros" entre ela e o mundo, que tem que conviver com vitórias e derrotas, aprender a vencer pelo esforço pessoal. Essas afirmações, ao desconsiderarem o contexto social, privilegiam o papel positivo - funcional para a educação física no processo educativo - que colabora para a funcionalidade e harmonia da sociedade vigente - e camuflam os disfuncionais, que quando identificados como negativos buscam causas e soluções em distorções da própria educação física. Em outras palavras, remetem para as condições internas da própria área, novamente num processo de isolamento.

Além do utilitarismo, o ecletismo também se faz presente nas formações, nos conteúdos específicos da educação física. Faz uma miscelânea de abordagens que susta qualquer possibilidade de ação. Há junção de autores e propostas pedagógicas de concepções opostas - críticas e não críticas ajustadas como se tivesse a mesma concepção de mundo, os mesmos interesses com a formação, e estas fossem as da Proposta Curricular.

Destaca-se, no conhecimento abordado, a apologia ao novo, mas este destituído do velho, sem inter-relação suficiente para identificar no "novo" as mesmas características do "velho" que se tenta matar, suprimir, inovar. 
Os conhecimentos abordados nas formações, no conjunto entre teórico-metodológicos e específicos de educação física, não se apresentam com profundidade suficiente para contribuir na promoção da compreensão da realidade em uma dimensão que possibilite pôr novas objetividades para a educação física.

Das nove formações realizadas, seis abordam o conhecimento dentro de uma matriz positivista. Três destas revestidas de pós-modernas por se apresentar como questionadoras do modelo "velho" e não apresentar alternativas a partir deste, maquiando o "novo" nas mesmas estruturas - estas compreendidas no limite de sua manifestação imediata. Duas apresentam o conhecimento eclético nos limites da Proposta, o que configura conhecimento das bases teóricas da Proposta, mas sem a profundidade necessária para a possibilidade de consolidá-la, e somente uma aponta o conhecimento na perspectiva materialista histórica.

Dentre as formações, seis apresentam o conhecimento advindo das ciências sociais e três das ciências naturais. Portanto, tanto as formações consubstanciadas nas ciências naturais como nas sociais - exceto uma - têm o mundo empírico como pano de fundo, o que para Bhaskar (1977) não permite a compreensão da realidade que fica no limiar da manipulação dos dados da realidade na prática imediata o que coíbe a possibilidade de almejar a superação da realidade das formações em Santa Catarina.

Destaca-se ainda a presença, nas formações, de posturas teóricas exortativas que como apontado por Avila (2008) aparecem como discursos e formas defendidas para a prática, mas que não implicam em nenhuma efetividade no fazer pedagógico dos professores.

Os conteúdos não se vinculam a um projeto crítico de educação, articulados ao materialismo histórico. O conhecimento abordado nas formações está distante de um avanço na perspectiva de uma prática que considere a relação entre as premissas teórico-metodológicas com os conhecimentos específicos a serem ensinados, ou seja, avanço do conhecimento na perspectiva ontológica realista crítica, na qual para Bhaskar (1977) os objetos do conhecimento sejam considerados como estruturas e mecanismos que geram fenômenos e o conhecimento como um produto da atividade social da ciência. 
O conhecimento abordado, quase na totalidade das formações pesquisadas, se assenta sobre uma concepção ontológica realista empírica, ou seja, vê a realidade no limite da experiência humana imediata, o que o mantém superficial, eclético e insuficiente para conhecer os nexos causais que determinam a realidade, o que dificulta as possibilidades de novas objetivações para a educação física na perspectiva da formação humana para a emancipação.

\section{REFERÊNCIAS}

AVILA, Astrid Baecker. A pós-graduação em educação física e as tendências na produção do conhecimento: o debate entre realismo e antirealismo. 2008. Tese (Doutorado) - Programa de Pós-Graduação em Educação, Universidade Federal de Santa Catarina. Florianópolis, 2008.

BHASKAR, Roy. A Realist Theory of Science. London, Verso, 1977. Versão Preliminar: Rodrigo Leitão (UFF). Tradução: Rodrigo Moerbeck (UFF). Revisão/Supervisão: Mário Duayer (UFF).

Societies. Capítulo 8, em Archer et al. (eds.) Critical Realism: Essential Readings. Routledge, London, 1998. Tradução preliminar: Herman Mathow/Thais Maia. Revisão: Bruno Moretti/Lilian Paes. Supervisão/Revisão Técnica: Prof. Mario Duayer.

BRACHT, Valter. Educação Física e aprendizagem social. Porto Alegre: Magister. 1992.

LUKÁCS, György. Para uma ontologia do ser social II. São Paulo: Boitempo, 2013.

. Para uma ontologia do ser social I. São Paulo: Boitempo, 2012.

MORAES, Maria Célia Marcondes de. Indagações Sobre o conhecimento no campo da educação. Revista Perspectiva, Florianópolis, v.27, n. 2, 315-346, jul./dez. 2009.

Os "pós-ismos" e outras querelas ideológicas. Revista Perspectiva, Florianópolis, ano 14, n. 25, 45-59, jan./jun. 1996.

Recuo da Teoria. In: MORAES, Maria Célia M. (Org.). lluminismo às avessas: Produção de conhecimento e políticas de formação docente. Rio de Janeiro: DP\&A, 2003.

SANTA CATARINA, Secretaria de Estado da Educação, coordenadoria de ensino. Proposta Curricular de Santa Catarina: Uma contribuição para a 
escola pública do pré-escolar, $1^{\circ}$ grau, $2^{\circ}$ grau e educação de adultos. Florianópolis: 1991.

SANTA CATARINA, Secretaria de Estado da Educação e do Desporto. Proposta Curricular de Santa Catarina: Educação Infantil, Ensino Fundamental e Médio: Disciplinas curriculares. Florianópolis: COGEN, 1998.

SAVIANI, Dermeval. História das ideias pedagógicas no Brasil. Campinas. Autores Associados. 2008. 